\title{
Spironolactone Does Not Prevent Acute Mountain Sickness: A Prospective, Double-Blind, Randomized, Placebo- Controlled Trial by SPACE Trial Group (Spironolactone and Acetazolamide Trial in the Prevention of Acute Mountain Sickness Group)
}

\author{
Buddha Basnyat, MD, MSc, FACP, FRCP (E); Peter S. Holck, PhD; Matiram Pun, MBBS; \\ Stephen Halverson, MD; Piotr Szawarski, MD; Jeffrey Gertsch, MD; Mike Steif, EMT; Skip Powell, MD; \\ Subhash Khanal, MBBS; Anip Joshi, MBBS; Ravi Shankar; Jamie Karambay, MS; Hattie D. Alexander, MD; \\ Allyson Stone, MS; Candice Morrissey, MSPH; Beth H. Thompson, MD; \\ Jeremy Farrar, BSc, MBBS, FRCP, DPhil, OBE, SPACE Trial Group. \\ From the Nepal International Clinic, Kathmandu, Nepal (Dr Basnyat); Himalayan Rescue Association, Kathmandu, Nepal (Drs Basnyat, \\ Holck, Halverson, Szawarski, Gertsch, Steif, and Powell); Mountain Medicine Society of Nepal, Kathmandu, Nepal (Drs Pun, Khanal, and \\ Joshi and Mr Shankar); University of Calgary, Calgary, Alberta, Canada (Dr Pun); Albany Medical College, Albany, NY (Dr Karambay); \\ Kirksville College of Osteopathic Medicine, Kirksville, MO (Dr Alexander); University of Utah School of Medicine, Salt Lake City, UT (Drs \\ Stone and Morrissey); Morecambe Bay Health Care Trust, Cumbria, Lancashire, UK (Dr Thompson); and Oxford University Clinical \\ Research Unit-Vietnam, Hanoi, Vietnam (Dr Farrar).
}

Objectives.-Over the last 20 years a number of small trials have reported that spironolactone effectively prevents acute mountain sickness (AMS), but to date there have been no large randomized trials investigating the efficacy of spironolactone in prevention of AMS. Hence, a prospective, double-blind, randomized, placebo-controlled trial was conducted to evaluate the efficacy of spironolactone in the prevention of AMS.

Methods.-Participants were sampled from a diverse population of western trekkers recruited at $4300 \mathrm{~m}$ on the Mount Everest base camp approach (Nepal side) en route to the study endpoint at $5000 \mathrm{~m}$. Three hundred and eleven healthy trekkers were enrolled, and 251 completed the trial from October to November 2007. Participants were randomly assigned to receive at least 3 doses of spironolactone $50 \mathrm{mg}$ BID, acetazolamide $250 \mathrm{mg}$ BID, or visually matched placebo. A Lake Louise AMS Score of 3 or more, together with the presence of headache and 1 other symptom, was used to evaluate the incidence and severity of AMS. Secondary outcome measures were blood oxygen content and the incidence and severity of high altitude headache (HAH).

Results.-Acetazolamide was more effective than spironolactone in preventing AMS (OR $=0.28$, $95 \%$ CI $0.12-0.60, p<0.01$ ). Spironolactone was not significantly different from placebo in the prevention of AMS. AMS incidence for placebo was $20.3 \%$, acetazolamide $10.5 \%$, and spironolactone $29.4 \%$. Oxygen saturation was also significantly increased in the acetazolamide group ( $83 \% \pm 0.04)$ vs spironolactone group $(80 \% \pm 0.05, \mathrm{p}<0.01)$.

Conclusions.-Spironolactone (50 mg BID) was ineffective in comparison to acetazolamide (250 $\mathrm{mg}$ BID) in the prevention of AMS in partially acclimatized western trekkers ascending to $5000 \mathrm{~m}$ in the Nepali Himalaya.

Key words: altitude sickness, spironolactone, acetazolamide, chemoprophylaxis, Himalaya, trekkers, Nepal 


\section{Introduction}

Acute mountain sickness (AMS) occurs primarily at altitudes greater than $2500 \mathrm{~m}$ and results from poor acclimatization. AMS is characterized by headache, lightheadedness, fatigue, nausea, and insomnia. ${ }^{1,2} \mathrm{Un}-$ treated, this symptom complex may lead to life-threatening high-altitude cerebral edema (HACE) or highaltitude pulmonary edema (HAPE). ${ }^{3}$ While a slow, careful ascent can significantly reduce or prevent AMS, drugs have also been shown to be effective. ${ }^{4,5}$ Preventive drugs may be necessary when a rapid ascent is required, as in high-altitude rescues or pilgrimages to mountains, flying in to high-altitude airports, military operations, and mountain climbing or trekking undertaken by those susceptible to AMS. Acetazolamide is currently the "gold standard" ",4,5 agent used for AMS prevention. However, side effects such as distressing paresthesias, dysgeusia, and diuresis can occur and therefore reduce compliance. ${ }^{4,5}$ Furthermore, people with sulfa allergy should avoid this drug.

Since up to $35 \%$ of trekkers may suffer from AMS while climbing to $5000 \mathrm{~m},{ }^{6}$ a safe and effective alternative to acetazolamide would be welcomed.

Spironolactone, an aldosterone antagonist and a mild diuretic, is an inexpensive drug that has shown promise in the prevention of AMS in a number of very small trials. $^{7-10}$ The efficacy of spironolactone is plausible since those persons developing AMS while trekking may have a higher aldosterone level, ${ }^{11,12}$ mediated through the activation of the renin angiotensin mechanism triggered by the stress of exercise. This may help retain more water and sodium, leading to over-perfusion of capillary beds and capillary leakage in the setting of a hypoxic environment.

Spironolactone may also generate a mild metabolic acidosis, but this is usually only seen in elderly patients and those with renal failure and cirrhosis. ${ }^{13-15}$ Although the exact process of AMS is unknown, factors such as water and sodium retention may predispose to AMS. ${ }^{4}$ Hence, in theory an aldosterone antagonist could prove useful by blocking the effect of aldosterone in Himalayan trekkers.

To date there have been no large randomized controlled trials comparing spironolactone to acetazolamide or placebo in the prevention of AMS. The primary objective of this study was to determine if 50 mg BID of spironolactone is more effective than placebo, and the secondary objective was to compare 50 $\mathrm{mg}$ BID spironolactone with acetazolamide $250 \mathrm{mg}$ BID in the prevention of AMS, as judged by the Lake Louise Questionnaire (LLQ) ${ }^{1,6}$

\section{Methods}

This investigation is a prospective, randomized, doubleblind, placebo-controlled trial. Enrollment occurred between October 6 and November 24, 2007 along the Mount Everest approach in the Nepali Himalaya. We obtained ethical approval from the Nepal Health Research Council and Oxford Tropical Research Ethics Committee (OXTREC). We also registered the trial internationally (ISRCTN77054547).

\section{OUTCOME MEASURES}

The predetermined primary outcome measures were incidence and severity of AMS at the study endpoint, ${ }^{16}$ based upon the Lake Louise AMS Scoring System. AMS is quantified on the LLQ as a score of 3 or greater, and must include headache plus at least 1 of the following symptoms: nausea or vomiting, fatigue, dizziness, or difficulty sleeping. The secondary endpoints we examined included headache incidence together with severity as measured on the LLQ, and oxygen saturation measured by resting pulse oximetry (Nonin Medical Products Inc., Minneapolis, MN). Demographic data, ascent profile, and compliance were analyzed to identify potential bias.

\section{STUDY SELECTION}

\section{Inclusion criteria}

Healthy non-Nepali male and female subjects between the ages of 18 and 65 without AMS or any concurrent illness, and not already taking acetazolamide or any other drug for the prevention of altitude illness, were included. Subjects who were en route to Everest Base Camp or Kalpattar were recruited and enrolled at Pheriche by study administrators.

\section{Exclusion criteria}

Otherwise eligible individuals were excluded if they presented with:

1. Mild AMS (more than 1 mild symptom on the LLQ)

2. Significantly depressed oxygen saturation $(<75 \%)$

3 . Pregnancy or those who could not exclude the possibility of being pregnant or have missed menses by over 7 days

4. History of allergy to acetazolamide or other sulfa drugs

5. Individuals who were on ACE inhibitors (eg, enalapril) or other diuretics (eg, amiloride or triamterene) 


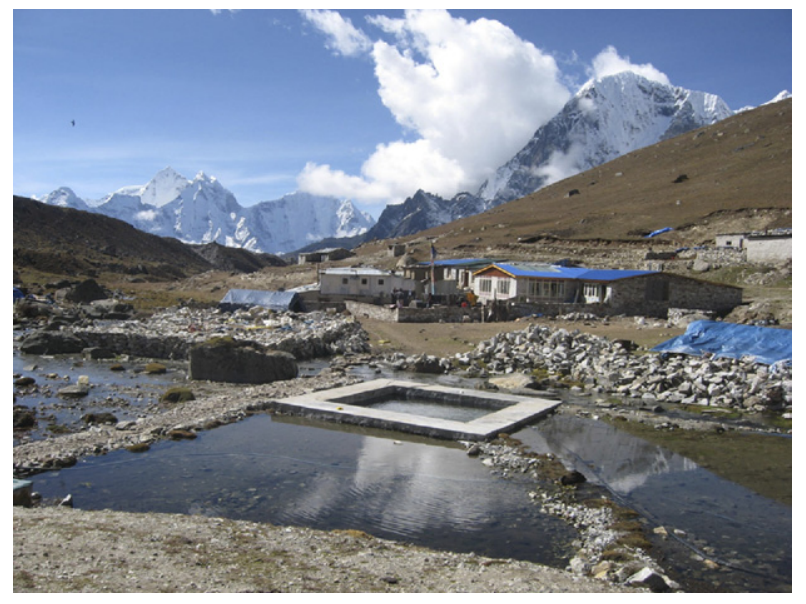

Figure 1. Lobuje: study endpoint.

6. Individuals who had spent 24 hours at an altitude of $4500 \mathrm{~m}(14,000 \mathrm{ft})$ within the last 9 days

7. Individuals known to have taken any of the following in the prior 2 days: acetazolamide (Diamox), steroids (dexamethasone, prednisone), theophylline, or diuretics (furosemide)

8. Individuals failing to provide informed consent at the study enrollment site at Pheriche

\section{INTERVENTION}

This was a prospective 3-armed, double-blind, randomized, placebo-controlled trial. Randomization of spironolatone, acetazolamide, and placebo was conducted by Deurali-Janta Pharmaceuticals Pvt. Ltd. (Kathmandu, Nepal). Small differences apparent in baseline covariates between treatment groups fell well within the expected range of that due to chance (chi-square and t-tests), supporting the conclusion that the randomization was appropriate.

After consent was obtained, each participant was given a 4-day supply of visually identical spironolactone $50 \mathrm{mg}$ BID, acetazolamide $250 \mathrm{mg}$ BID, or placebo BID. Trekkers were enrolled in the study and baseline measurements were taken at the village of Pheriche (4300 $\mathrm{m})$, and reassessed following their arrival at the study endpoint in Lobuje $(5000 \mathrm{~m})$ (Figure 1). This reassessment occurred between 30 hours and 4 days after taking the study drug. Both initial and final (Pheriche and Lobuje) study assessments and measurements used the LLQ and oxygen saturation with a pulse oximetry.

\section{PRIMARY AND SECONDARY OUTCOMES}

Main outcome measure was the incidence of AMS, as measured by Lake Louise acute mountain sickness score $\geq 3$ with headache, and at least 1 other symptom.

Secondary outcome measures include oxygen saturation measured by pulse oximeter, severity of symptoms (LLscore $\geq 5$ ), incidence of headache, and severity of headache $(\geq 2)$.

\section{STUDY MONITORING}

Study administrators were present at both the recruiting site and the endpoint site. Three sealed master lists of the randomization code were held by the manufacturer, an independent clinician at the Nepal International Clinic in Katmandu, and an independent clinician at the aid post in Pheriche (study enrollment location). Upon concern of allergic reaction or any other adverse event requiring knowledge of the patient's medication history, the code would be opened by an independent clinician who was not a study author.

\section{SAMPLE SIZE}

Based on a previous study, ${ }^{6}$ AMS incidence at study endpoint of $5000 \mathrm{~m}$ in Lobuje was expected to be approximately $34 \%$ for participants taking placebo, and $12 \%$ for participants using acetazolamide. For sample size calculations, we hypothesized that spironolactone would produce similar protection rates to that of acetazolamide. Setting $\alpha=0.05$ and using $80 \%$ power, a sample of 57 participants would be necessary in each arm to detect a significant difference between spironolactone and placebo. Anticipating a 10\% drop out rate, we planned to recruit 63 volunteers in each of the placebo and spironolactone arms. Our primary interest was the efficacy of spironolactone compared to acetazolamide. However, we felt it important and responsible to first demonstrate the efficacy of spironolactone compared to placebo. Because we anticipated recruiting more than 126 volunteers (63 in 2 arms), we capped assignment to placebo at 63 . We then randomly allocated other recruited individuals evenly between spironolactone and acetazolamide (Figure 2). Increased sample sizes in these groups allowed a more precise estimate of each possible treatment effect, and potentially permit identification of statistical differences in treatment efficacy.

\section{STATISTICAL ANALYSIS}

Odds ratios and associated confidence intervals (asymptotic or using Fishers exact test) were used to estimate effects of categorical variables. Initial univariate examination of potential predictors of AMS were assessed 


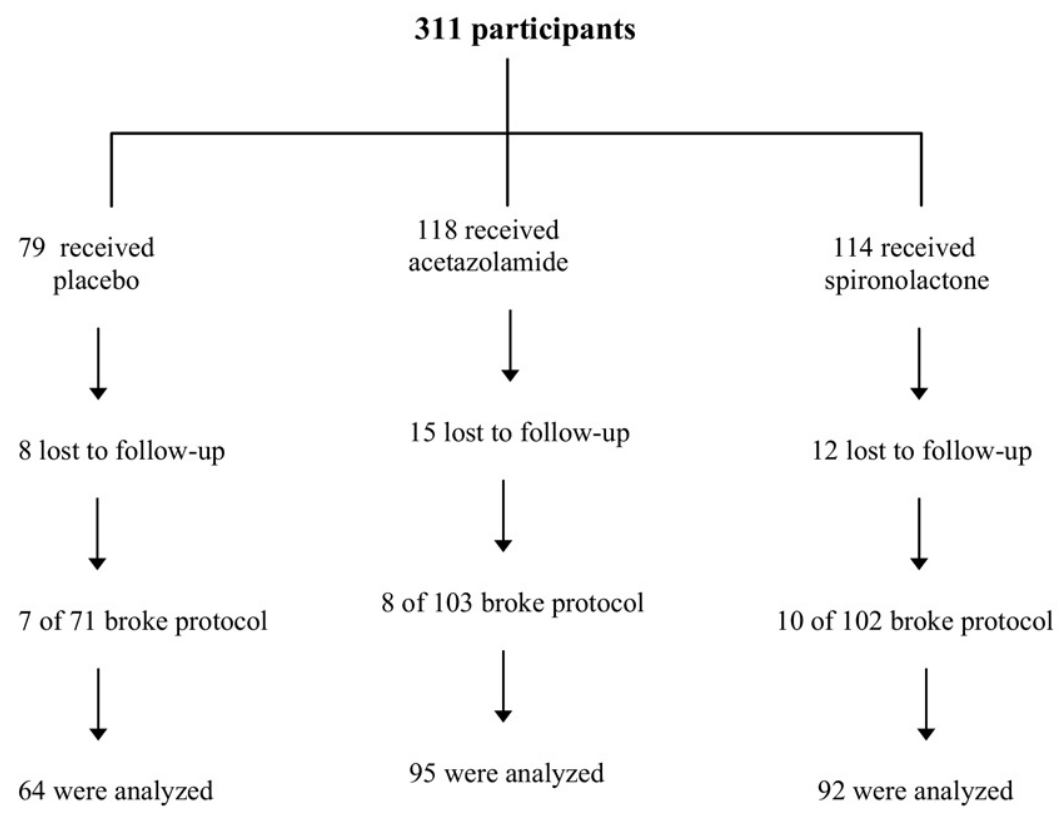

Figure 2. Study flow chart.

using t-tests or chi-square tests. t-Tests were used to compare means of continuous outcomes. Multivariate models were incorporated to investigate the effect of potential confounders (age, gender, mode of arrival, and a measure of prior acclimatization-the number of nights spent above a particular elevation-were included in the models). In all cases $p$-values less than 0.05 were considered significant. All analysis was conducted using R version 2.11 (R Foundation for Statistical Computing, Vienna, Austria).

\section{Results}

\section{BASELINE EVALUATION}

There were a total of 311 trekkers enrolled in the study with 251 subjects completing the questionnaires at the endpoint (see Figure 2). The general baseline similarity between all participants in the 3 groups is shown in Table 1 . Participants who were lost to follow-up had a similar demographic profile to those completing the study.

\section{ENDPOINT EVALUATIONS}

The main outcome profile for the 251 participants who completed the study is summarized in Table $2 \mathrm{a}$ and Table $2 b$. There were no major adverse events such as high altitude pulmonary or cerebral edema, anaphylaxis, or serious adverse reactions to acetazolamide or spironolactone.

Multivariate analysis (controlling for age, gender, rate of ascent) revealed acetazolamide was more effective than spironolactone in preventing AMS. In addition, spironolac-

Table 1. Baseline characteristic of the completed study group

\begin{tabular}{lcccc}
\hline & $\begin{array}{c}\text { All study participants } \\
n=251\end{array}$ & $\begin{array}{c}\text { Acetazolamide group } \\
n=95\end{array}$ & $\begin{array}{c}\text { Placebo group } \\
n=64\end{array}$ & $\begin{array}{c}\text { Spironolactone group } \\
n=92\end{array}$ \\
\hline Female gender & $31.5 \%(79)^{a}$ & $37.9 \%(36)$ & $28.1 \%(18)$ & $27.2 \%(25)$ \\
Male gender & $68.5 \%(172)$ & $62.1 \%(59)$ & $71.9 \%(46)$ & $72.8 \%(67)$ \\
Mean age \pm std error & $38 \pm 12.7$ & $37.2 \pm 12$ & $39.4 \pm 13.1$ & $37.7 \pm 12.8$ \\
Trekkers starting from $2800 \mathrm{~m}^{b}$ & $84.5 \%(212)$ & $83.2 \%(79)$ & $84.4 \%(54)$ & $85.9 \%(79)$ \\
Nights to ascend from $2800 \mathrm{~m}$ & $4.59 \pm 1.37$ & $4.60 \pm 1.22$ & $4.53 \pm 1.30$ & $4.62 \pm 1.57$ \\
Baseline oxygen saturation & $85 \% \pm 0.05$ & $85 \% \pm 0.05$ & $85 \% \pm 0.05$ & $85 \% \pm 0.05$ \\
\hline
\end{tabular}

\footnotetext{
${ }^{a}$ Numbers in parenthesis are the total count; \pm followed by estimated standard error.

${ }^{b}$ Some trekkers walked up from Jiri (1900 m): 9, 15, and 13 trekkers in the placebo, acetazolamide, and spironolactone groups, respectively, walked up from Jiri. Two flew into Phaplu and trekked up.
} 
Table 2a. Main outcome profile (multivariate analysis ${ }^{e}$ ) comparing groups treated with prophylactic agents for acute mountain sickness to the placebo group. Values in parenthesis are counts unless otherwise noted

\begin{tabular}{|c|c|c|c|c|c|c|}
\hline Outcome & $\begin{array}{c}\text { All } \\
n=251\end{array}$ & $\begin{array}{c}\text { Placebo } \\
n=64 \\
25 \%\end{array}$ & $\begin{array}{c}\text { Acetazol- } \\
\text { amide } \\
n=95 \\
38 \%\end{array}$ & $\begin{array}{c}\text { Spirono- } \\
\text { lactone } \\
n=92 \\
37 \%\end{array}$ & $\begin{array}{c}\text { Odds Ratio }{ }^{a} \\
\text { Ace. vs Placebo } \\
(95 \% \text { CI })\end{array}$ & $\begin{array}{c}\text { Odds Ratio } \\
\text { Spiro. vs Placebo } \\
(95 \% \text { CI })\end{array}$ \\
\hline Incidence of AMS & $19.9 \%(50)$ & $20.3 \%(13)$ & $10.5 \%(10)$ & $29.4 \%(27)$ & $\begin{array}{c}0.46(0.18-1.13) \\
p=0.09\end{array}$ & $\begin{array}{c}1.66(0.78-3.66) \\
p=0.19\end{array}$ \\
\hline Severe AMS LLS ${ }^{b}>5$ & $7.9 \%(20)$ & $14 \%(9)$ & $4.2 \%(4)$ & $7.6 \%(7)$ & $\begin{array}{c}0.23(0.06-0.77) \\
p=0.02\end{array}$ & $\begin{array}{c}0.47(0.16-1.37) \\
p=0.17\end{array}$ \\
\hline Headache & $38.6 \%(97)$ & $35.9 \%(23)$ & $29.5 \%(28)$ & $50 \%(46)$ & $\begin{array}{c}0.76(3.80-1.52) \\
p=0.43\end{array}$ & $\begin{array}{c}1.80(0.93-3.52) \\
p=0.08\end{array}$ \\
\hline Severe Headache $\left(\geq 2\right.$, LLS $\left.^{b}\right)$ & $7 \%(18)$ & $10.9 \%(7)$ & $3.1 \%(3)$ & $8.7 \%(8)$ & $\begin{array}{c}0.23(0.05-0.91) \\
p=0.054\end{array}$ & $\begin{array}{c}0.77(0.25-2.4) \\
p=0.65\end{array}$ \\
\hline $\begin{array}{l}\text { Mean end point (\%) oxygen sat. } \\
\text { Non-compliant }^{d}\end{array}$ & $\begin{array}{c}81 \pm 0.05^{c} \\
25\end{array}$ & $\begin{array}{c}80 \pm 0.04 \\
7\end{array}$ & $\begin{array}{c}83 \pm 0.04 \\
8\end{array}$ & $\begin{array}{c}80 \pm 0.05 \\
10\end{array}$ & $p<0.01$ & $p=0.80$ \\
\hline \multicolumn{7}{|c|}{$\begin{array}{l}{ }^{a} \text { Compared with incidence in placebo group. } \\
{ }^{b} \text { Lake Louise Score. }{ }^{13} \\
{ }^{c} \text { Estimated standard error. } \\
{ }^{d} \text { Took acetazolamide outside study protocol or }>2 \text { consecutive doses missed. } \\
{ }^{e} \text { Multivariate logistic model included covariates age, gender, mode of arrival to study location (plane, walk), and a measure of prior } \\
\text { climatization. }\end{array}$} \\
\hline
\end{tabular}

tone did not reduce AMS incidence when compared with placebo; nor did it show a benefit as compared to placebo for any secondary outcome measures (Table $2 \mathrm{a}$ ). The observed elevated incidence and severity of AMS and headache observed in the spironolactone group as compared directly with placebo was not statistically significant.
Acetazolamide was observed to have lower incidence of AMS, lower headache incidence and severity, and significantly improved blood oxygen saturation with ascent when compared directly with placebo (Table $2 \mathrm{a}$; statistical significance observed only in AMS severity and oxygen saturation).

Table 2b. Main outcome profile (multivariate analysis ${ }^{e}$ ) comparing treatment with prophylactic agents acetazolamide and spironolactone for acute mountain sickness. Values in parenthesis are counts unless otherwise noted

\begin{tabular}{|c|c|c|c|c|}
\hline Outcome & $\begin{array}{c}\text { All } \\
\text { Participants } \\
n=251\end{array}$ & $\begin{array}{c}\text { Acetazol-amide } \\
n=95\end{array}$ & $\begin{array}{l}\text { Spirono- } \\
\text { lactone } \\
n=92\end{array}$ & $\begin{array}{c}\text { Odds Ratio } \\
\text { (95\% CI) Ace. } \\
\text { vs Spiro }\end{array}$ \\
\hline Incidence of AMS & $19.9 \%(50)$ & $10.5 \%(10)$ & $29.4 \%(27)$ & $\begin{array}{c}0.28(0.12-0.60) \\
p<0.01\end{array}$ \\
\hline Severe AMS LLS ${ }^{b}>5$ & $7.9 \%(20)$ & $4.2 \%(4)$ & $7.6 \%(7)$ & $\begin{array}{c}0.49(0.12-1.72) \\
p=.28\end{array}$ \\
\hline Headache & $38.6 \%(97)$ & $29.5 \%(28)$ & $50 \%(46)$ & $\begin{array}{c}0.42(0.23-0.78) \\
p<0.01\end{array}$ \\
\hline Severe Headache $\left(\geq 2, \mathrm{LLS}^{b}\right)$ & $7 \%(18)$ & $3.1 \%(3)$ & $8.7 \%(8)$ & $\begin{array}{c}0.30(0.06-1.12) \\
p<0.09\end{array}$ \\
\hline $\begin{array}{l}\text { Mean end point oxygen } \\
\text { saturation }(\%)\end{array}$ & $81 \pm 0.05^{c}$ & $83 \pm 0.04$ & $80 \pm 0.05$ & $p<0.01$ \\
\hline Non-compliant ${ }^{d}$ & 25 & 8 & 10 & \\
\hline
\end{tabular}

\footnotetext{
${ }^{b}$ Lake Louise Score. ${ }^{13}$

${ }^{c}$ Estimated standard error.

${ }^{d}$ Took acetazolamide outside study protocol or $>2$ consecutive doses missed.

${ }^{e}$ Multivariate logistic model included covariates age, gender, mode of arrival to study location (plane, walk), and a measure of prior acclimatization.
} 


\section{EVALUATION FOR POTENTIAL BIAS}

Comparison between groups of ascent profile (Table 1) or noncompliance (Table $2 \mathrm{a}$ and Table $2 \mathrm{~b}$ ) revealed no indication of bias. Incorporating an intent-to-treat approach, whereby the individuals excluded due to medication use outside their prescribed treatment regime were included in the analysis, yielded only minor differences in estimated treatment effects (and no change in statistical significance of these effects).

\section{Discussion}

Acetazolamide was more effective than spironolactone in preventing AMS. In addition, spironolactone was not effective in reducing the incidence or severity of AMS as compared with placebo, and failed to show a protective benefit for any outcome measure, including endpoint oxygen saturation. Based on previous studies, ${ }^{11,12}$ which showed that AMS symptoms score was associated with elevated aldosterone levels at high altitude on Mount Kenya and the European Alps, we hypothesized that an aldosterone antagonist may be useful by blocking the effect of aldosterone in trekkers to high altitude in the Himalayas.

A number of methodological differences may explain the contradictions between our findings and those of previous studies. $^{7-9}$ One of the studies ${ }^{9}$ was a hypobaric chamber study where subjects were exposed to an altitude of $4570 \mathrm{~m}$ for 46 hours. This may not simulate outdoor trekking conditions as in our study. As AMS is altitude-dependent, another study ${ }^{7}$ was different from ours because it was carried out at $3500 \mathrm{~m}$, unlike ours whose starting point was $4300 \mathrm{~m}$. Two other studies ${ }^{8,10}$ originated at around $3000 \mathrm{~m}$. In all the previous studies, spironolactone was administered 48 hours before participants ascended altitudes higher than $3000 \mathrm{~m}$. In the previous studies all the participants took spironolactone for at least 48 hours at high altitude (both these points are again addressed under limitations of the study). In all the studies, the spironolactone dosage used was 100 $\mathrm{mg}$, as in our study, except in $1 \mathrm{study}^{8}$ where they used $75 \mathrm{mg}$ per day. Clinically spironolactone can be used up to $100 \mathrm{mg}$ QID especially in the treatment of cirrhosis. It is possible that at a higher dosage the drug could be beneficial in the prevention of AMS.

While our study used the LLQ, previous studies used less well-defined questionnaires as they all predated the LLQ. ${ }^{4}$ While ours was a large double-blind, randomized study, 2 of the other studies ${ }^{7,9}$ were blinded and randomized and 2 were not. ${ }^{8,10}$ Most importantly, unlike our study, which recruited 311 people, the largest previous study ${ }^{7}$ had a sample size of 29 people, and other studies noted $^{8,9}$ enrolled just 9 and 13 subjects.

\section{LIMITATIONS OF THE STUDY}

Spironolactone has a slow onset of action, with peak effect occuring 48 to 72 hours ${ }^{17}$ after administration. Most participants in the spironolactone group (71 out of 92) were examined at about 34 hours after taking the drugs. It is therefore likely that peak effect of spironolactone on aldosterone inhibition had yet to be achieved when outcome measures were recorded. However, 21 participants who had taken spironolactone for $>48$ hours when the endpoint assessment at Lobuje was made were not found to be any different than those taking spironolactone that were measured earlier (data not shown). Furthermore, acetazolamide typically is effective within hours of administration, ${ }^{18}$ an important advantage as most people prefer a drug that works rapidly. Thus, even if efficacy of spironolactone improved by incorporating a longer administered lead time, it is not clear the drug would appeal to trekkers. In addition, a rapidly acting drug is required during times of rescue. We chose to assign fewer participants to the placebo group than to the other treatment arms. Many earlier studies ${ }^{6,19-21}$ have already determined that acetazolamide is more effective than placebo in the prevention of AMS; thus our primary interest was to accurately assess and compare efficacy of spironolactone and acetazolamide. Our sampling strategy therefore assigned any additional persons enrolled (beyond those determined necessary to confirm previous comparisons of acetazolamide and placebo) to acetazolamide and spironolactone arms (randomized), allowing us to more accurately estimate the efficacy of each of these treatments. While this approach results in a less precise estimate of AMS among those on placebo, this has been adequately measured in numerous previous studies. Unlike our previous studies, ${ }^{6,20,21}$ the acetazolamide group was not significantly better protected than the placebo group ( $p=0.09$ ), a result we attribute to the reduced number of participants assigned to the placebo group. The study sample and design was not powered to distinguish between placebo and acetazolamide. Since we undersampled the number of participants randomly assigned to placebo so that we could have more participants assigned to the 2 treatment groups, our estimate of the relative "benefits" of placebo treatment may not be particularly precise. Although statistically insignificant, the latter may also be the reason why participants on spironolactone had more AMS $(29.4 \%$ vs $20.3 \%$, Table 2a) than the placebo group.

It is also possible that the true efficacy of acetazolamide is less than previously assumed (and thus less than 
utilized in our power calculations). Certainly our sample of 64 in placebo group and 95 in acetazolamide treatment group yielded a smaller estimate of the efficacy of acetazolamide (only $10 \%$ fewer persons in the acetazolamide group reported AMS), although this sample is smaller than other studies upon whose results we based our power calculations (studies completed on the same ascent profile). Differences may well be attributable to random chance in the characteristics of the individuals assigned to each treatment group.

The choice of the study baseline is unusually high $(4300 \mathrm{~m})$; many potential participants may suffer from AMS below this altitude, and may have stopped ascending. Hence, there may be a degree of "self-selection" in our participants. However, our study participants did rapidly ascend $700 \mathrm{~m}$ from Pheriche to Lobuje along the same route in generally the same time frame. It is true that comparison with other studies that employ a lowaltitude baseline may be difficult. However, our previous studies $^{6,20,21}$ show clearly that high rates of AMS can be expected at the endpoint altitude (Lobuje) as compared with the baseline altitude (Pheriche), making drug intervention trials possible in these partially acclimatized trekkers. Enrolling participants at villages at lower altitude (eg, Namche Bazaar) is logistically difficult given the increased potential dropout rates and numerous trekking destinations and durations.

In this field study, we were unable to assess the fluid status or salt intake of participants, ${ }^{22}$ which could potentially influence aldosterone levels. Study administrators did, however, instruct participants at enrollment (Pheriche) that drinking adequate amounts of fluid was important to remaining healthy at high altitude. Measurement of weight, urinary volume, and serum bicarbonate would also have added to the scientific rigor of the study.

Finally, a large number of participants suffered from paresthesias in the acetazolamide group in keeping with the findings in our previous study. ${ }^{21}$ Although we did not inquire about the severity of the paresthesia, for many this tingling sensation in the fingers and toes is very distressing. Discomforting paresthesias may continue to be the main reason some people wish to avoid acetazolamide even when indicated. Although sulfa allergy may be a potential problem in the usage of acetazolamide, there seems to be little cross-reactivity between antibiotic sulfonamide (eg, trimethoprim-sulfamethoxale) and nonantibiotic sulfonamide (acetazolamide) ${ }^{23}$

\section{Conclusion}

In conclusion, this study of partially acclimatized participants in the Nepali Himalaya has shown that spironolactone (50 mg BID) was inferior to acetazolamide (250 mg BID) in the prevention of AMS. Indeed spironolactone was not shown to offer any benefit over placebo. Clinicians and policy makers should continue to recommend acetazolamide as the drug of choice for the prevention of AMS. However, all drugs carry the risk of adverse reactions. Therefore, ascending slowly and cautiously remains the best way to prevent AMS and its threatening complications.

\section{Acknowledgements}

Funding for this study was provided by Wellcome Trust, UK. We would like to thank all the staff of the Himalayan Rescue Association in Nepal. We are especially indebted to the trekker participants who were very kind to enroll in our study. We would like to thank Dr Jim Milledge for his advice. Finally, our thanks to The Wellcome Trust, Euston Road, London, United Kingdom for helping with this study.

\section{References}

1. Wilson MH, Newman S, Imray CH. The cerebral effects of ascent to high altitudes. Lancet Neurol. 2009;8:175-191.

2. Basnyat B, Tabin G. Altitude Illness: Acute mountain sickness, high-altitude pulmonary edema, and high-altitude cerebral edema. In: Fauci AS, Braunwald E, Kasper DL, et al, eds. Harrison's Principles of Internal Medicine. 17th ed. 2008. Available at: http://www.accessmedicine.com/ content.aspx?aID $=2908650$.

3. Stream JO, Grissom CK. Update on high-altitude pulmonary edema: pathogenesis, prevention, and treatment. Wilderness Environ Med. 2008;19:293-303.

4. Hackett PH, Roach RC. High altitude illness. $N$ Engl J Med. 2001;345:107-114.

5. Basnyat B, Murdoch D. High altitude illness: an update of pathophysiology, prevention, and treatment. Lancet. 2003; 361:1967-1974.

6. Gertsch JH, Basnyat B, Johnson EW, Onopa J, Holck PS. Randomised, double blind, placebo controlled comparison of ginkgo biloba and acetazolamide for prevention of acute mountain sickness among Himalayan trekkers: the prevention of high altitude illness trial (PHAIT). BMJ. 2004;328: 797-799. Available at: http://www.bmj.com/content/ 328/7443/797.long.

7. Jain SC, Singh MV, Sharma VM, Rawal SB, Tyagi AK. Amelioration of acute mountain sickness: comparative study of acetazolamide and spironolactone. Int J Biometeorol. 1986;30:293-300.

8. Currie TT, Carter PH, Champion WL, et al. Spironolactone and acute mountain sickness. Med J Aust. 1976;2: $168-170$.

9. Larsen RF, Rock PB, Fulco CS, et al. Effect of spironolactone on acute mountain sickness. Aviat Space Environ Med. June 1986;57:543-547. 
10. Anonymous. Spironolactone in acute mountain sickness. Lancet. 1977;1:855.

11. Bartsch P, Shaw S, Franciolli M, et al. Atrial natriuretic peptide in acute mountain sickness. J Appl Physiol. 1988; 65,1929-1937.

12. Milledge JS, Beeley JM, McArthur S, Morice AH. Atrialnatriuretic peptide, altitude and acute mountain sickness. Clin Sci. 1989;77:509-514.

13. Henger A, Tutt P, Riesen WF, et al. Acid-base and endocrine effects of aldosterone and angiotensin II inhibition in metabolic acidosis in human patients. J Lab Clin Med. 2000;136:379-389.

14. Hulter HN, Bonner EL Jr, Glynn RD, et al. Renal and systemic acid-base effects of chronic spironolactone administration. Am J Physiol. 1981;240:F381-F387.

15. Kreisberg RA, Wood BC. Drug and chemical-induced metabolic acidosis. Clin Endocrinol Metab. 1983;12: 391-411.

16. Roach RC, Bartsch P, Hackett PH, Oelz O. The Lake Louise AMS Scoring Consensus Committee. The Lake Louise acute mountain sickness scoring system. In: Sutton JR, Coates G, Huston CS, eds. Hypoxia and Molecular Medicine: Proceedings of the 8th International Hypoxia Symposium, 9-13 February 1993; Lake Louise, Alberta, Canada. Burlington, VT: Queen City Printers, 1993:272-274.
17. Pitt B, Zannad F, Remme WJ. The effect of spironolactone on morbidity and mortality in patients with severe heart failure. N Engl J Med. 1999;341:709-717.

18. Hackett PH, Roach RC: High altitude medicine. In Auerbach P, ed. Wilderness Medicine. 5th ed. Philadelphia: Mosby Elsevier; 2007, 2-36.

19. Hackett PH, Rennie D, Levine HD. The incidence, importance, and prophylaxis of acute mountain sickness. Lancet. 1976;2:1149-1154.

20. Basnyat B, Gertsch JH, Johnson EW, et al. Efficacy of low-dose acetazolamide (125 mg BID) for the prophylaxis of acute mountain sickness. High Alt Med Biol. 2003;4: 45-52.

21. Basnyat B, Gertsch JH, Holck PS, et al. Acetazolamide 125 $\mathrm{mg} \mathrm{BD}$ is not significantly different from $375 \mathrm{mg}$ BD in the prevention of acute mountain sickness: the prophylactic acetazolamide dosage comparison for efficacy (PACE) trial. High Alt Med Biol. 2006;7(1):17-27.

22. Milledge JS. Salt and water control at altitude. Int J Sports Med. 1992;13(suppl 1):S61-S63.

23. Strom BL, Schinnar R, Apter AJ, et al. Absence of crossreactivity between sulfonamide antibiotics and sulfonamide nonantibiotics. $N$ Engl J Med. 2003;349: $1628-1635$. 